\title{
Comparação dos gastos com material para reparação de perfurações de córnea com cola de cianoacrilato e sutura de córnea
}

\author{
Comparative cost evaluation in corneal perforation repair with cyanoacrylate adhesive \\ versuscorneal suture
}

Emerson Lioji Ueda ${ }^{1}$

José Auǵusto Alves Ottaiano ${ }^{2}$
Este trabalho faz parte da tese apresentada à Universidade Federal de São Paulo - UNIFESP para obtenção de Título de Mestre Profissional em Administração da Prática Oftalmológica

${ }^{1}$ Médico Colaborador da Disciplina de Oftalmologia da Faculdade de Medicina de Marília e Especialista contratado pela Disciplina de Oftalmologia da Faculdade de Medicina da Universidade de Marília - Unimar.

${ }^{2}$ Doutor Chefe da Disciplina de Oftalmologia da Faculdade de Medicina de Marília.

Endereço para correspondência: Av. Rio Branco, 86 Marília -SP - CEP 17500-090 - E-mail: elueda@uol.com.br

Recebido para publicação em 20.01.2003

Versão revisada recebida em 08.07.2003

Aprovação em 07.08.2003

\section{RESUMO}

Objetivo: Avaliação comparativa de custos de reparação de pequenas perfurações oculares utilizando a técnica da cola de cianoacrilato Super Bonder ${ }^{\circledR}$ (2-metil-cianoacrilato) comparada à técnica de sutura de córnea. Métodos: A fim de avaliar comparativamente os custos do uso da técnica de cola de cianoacrilato com a técnica de sutura de córnea, realizou-se análise dos materiais usados em ambas técnicas. Resultados: A análise de custos comparativos entre o uso da técnica de cola de cianoacrilato em pequenas perfurações, versus a técnica de sutura de córnea demonstrou menor gasto com uso do adesivo. Conclusão: A utilização da técnica de cola de cianoacrilato, para reparação de perfuração de córnea, apresentou custos menores quando comparada com a técnica de sutura de córnea.

Descritores: Córnea/lesões; Custos de cuidados de saúde; Suturas/economia; Cianocrilatos/economia; Cola

\section{INTRODUÇ̃̃̃O}

O traumatismo ocular é importante causa de deficiência visual atingindo principalmente as crianças e adultos jovens ${ }^{(1-2)}$.

Apesar dos dados serem subestimados, calcula-se que o trauma ocular seja responsável por 1,5-2,0 milhões de novos casos de cegueira monocular por ano no mundo ${ }^{(3)}$.

De acordo com dados obtidos pelo United States Eye Injury Registry (USEIR) em 1977, há aproximadamente 2,4 milhões de trauma ocular nos Estados Unidos (EUA), anualmente. Segundo esses dados calcula-se que o trauma ocular seja responsável pelo comprometimento visual significante e permanente em quase 1 milhão de americanos, sendo que mais de $75 \%$ dos indivíduos desenvolvem cegueira monocular. O trauma ocular é a principal causa de cegueira monocular dos EUA e a segunda causa mais freqüente de comprometimento visual, após a catarata. Representa, também, a principal causa de admissões em hospitalares com envolvimento ocular ${ }^{(1,4)}$.

Ainda nos EUA, os dados de registro dos traumas oculares realizados em 1998 demonstraram que de 8.952 pacientes que apresentaram trauma ocular grave, $58 \%$ estavam na faixa etária abaixo de 30 anos, sendo mais freqüente no sexo masculino na proporção de $4,6: 1^{(1)}$.

Em estudo epidemiológico, realizado com 103 pacientes na Alemanha entre 1996 e 1997 encontrou-se como principais causas de trauma ocular os acidentes domésticos (38\%) e atividades laborativas (31\%), sendo que em $50 \%$ dos casos, metal e vidro foram os agentes ${ }^{(5)}$. 
No Brasil, há poucos dados referentes ao assunto ${ }^{(6)}$. Estima-se, pelos dados preliminares do Censo Demográfico 2000 do Instituto Brasileiro de Geografia e Estatística (IBGE), que a população do Brasil seja de aproximadamente 170 milhões de pessoas e que $14,5 \%$ da população apresenta alguma deficiência física ou mental. Desse total, $48,1 \%$ declararam apresentar alguma deficiência visual ${ }^{(7)}$.

Em trabalho realizado em Curitiba, no Instituto de Cegos do Paraná, no período de setembro a novembro de 1989, foram examinados 223 olhos, de 121 pacientes, sendo o traumatismo ocular responsável pela causa de cegueira em 20 olhos $(9 \%)^{(8)}$.

Num estudo retrospectivo de 400 casos realizado no Hospital de Clínicas da Faculdade de Medicina da Universidade de São Paulo, no período de janeiro de 1991 a dezembro de 1992, as principais causas de traumatismo perfurante ocular foram: acidentes de trânsito $(30,8 \%)$, domésticos $(27,8 \%)$, ocupacionais $(22,8 \%)$, lazer e esporte $(10,2 \%)$ e agressão $(8,5 \%)$. Enquanto os acidentes de trânsito ocorreram principalmente em pacientes na faixa etária de 21-30 anos (36,6\%), nos acidentes domiciliares a maior incidência ocorreu na faixa de 0-10 $\operatorname{anos}(42,3 \%)^{(9)}$.

Observou-se, no Pronto Socorro do Hospital São Paulo, que dos 159 olhos com perfuração ocular decorrentes de acidente automobilístico 54 apresentaram com perfurações de córnea $^{(10)}$.

Segundo a Organização Mundial de Saúde (OMS) a principal causa de cegueira no mundo, após a catarata, deve-se ao comprometimento da córnea, decorrente do traumatismo ocular e úlcera de córnea apresentando como as causas mais importantes de cegueira corneal ${ }^{(3)}$.

Dentre os vários tipos de trauma ocular, os traumatismos perfurantes requerem atendimentos emergenciais e necessitam de intervenções imediatas, pela gravidade dos danos que proporcionam e pelos altos custos que representam para a sociedade $^{(5)}$.

Calcula-se que nos EUA os traumas oculares relacionados aos acidentes de trabalho, representem custos de US\$ $300 \mathrm{mi}-$ lhões anualmente ${ }^{(1,4)}$. Na Austrália, ocorrem 29.000 casos novos de trauma ocular por ano com custo total de US $\$ 80$ milhões $^{(11)}$.

A alta prevalência de traumatismos oculares perfurantes enfatiza a importância em determinar-se a forma mais eficaz de tratamento dessas ocorrências ${ }^{(12-13)}$.

$\mathrm{O}$ uso de adesivos teciduais, para tratamento de afecções corneais com afinamento e micro-perfurações, é bastante divulgado e aceito ${ }^{(12-15)}$. $\mathrm{O}$ adesivo tecidual ideal para uso em oftalmologia é o n-butil-2-cianoacrilato, comercializado estéril, com baixa toxidade corneal e com o nome de Hystoacril Blue ${ }^{\circledR}$ (B. Braun Melsungen AG Melsungen, Alemanha) $)^{(15-16)}$.

No tratamento de perfurações de córnea de até $2 \mathrm{~mm}$ de diâmetro tem sido recomendada a utilização de cola de cianoacrilato e/ou lente de contato ${ }^{(13,15-16)}$. O adesivo, ao selar as perfurações de córnea, serve de apoio para o crescimento de tecido cicatricial sobre a área perfurada, além de inibir a migração de células inflamatórias, o que retarda a necrose corneal ${ }^{(17)}$.
A dificuldade em obtenção assim como o alto custo do Hystoacril Blue ${ }^{\circledast}$, em nosso meio, torna importante a busca de outros produtos com a finalidade de tratar as perfurações da córnea. $\mathrm{O}$ 2-metil-cianoacrilato (SUPER BONDER ${ }^{\circledR}$ ) comercializado para finalidades não médicas, tem sido utilizado com eficácia comprovada em oftalmologia ${ }^{(15,17)}$.

\section{OBJETIVO}

O objetivo deste estudo é comparar os custos do uso da cola de 2-metil-cianoacrilato e da sutura de córnea para tratamento de perfuração de córnea asséptica.

\section{MÉTODOS}

Este trabalho foi realizado na Faculdade de Medicina de Marília (FAMEMA), Disciplina de Oftalmologia, com a finalidade de avaliar comparativamente os custos do tratamento de perfurações de córnea de até $2,5 \mathrm{~mm}$ de diâmetro utilizando-se a cola de 2-metil-cianoacrilato e a sutura de córnea ${ }^{(13,17)}$. A cola utilizada foi a 2-metil-cianoacrilato, comercializada no Brasil com o nome comercial de Super Bonder ${ }^{\circledR}$ (Loctite).

Foram realizadas avaliações de preços dos materiais empregados para realização das duas técnicas junto a três fornecedores, tendo-se optado pela menor cotação para utilização de valores de todos os dos materiais similares.

Foram desconsiderados os custos com anestesia geral assim como despesas com "hospedagem hospitalar", devido ao alto índice de variação destes dados.

\section{Técnica com o uso de cola de cianoacrilato}

Materiais utilizados:

1. colírio de proparacaína a $0,5 \%$ ( $1 \mathrm{ml})$

2. colírio ofloxacina a $0,3 \%(1$ gota $=0,05 \mathrm{ml})$

3. 1 lâmina de bisturi ${ }^{\circ} 15$

4. 1 esponja de celulose

5. 1 agulha $25 \times 7$

6. 1 tubo de cola de cianoacrilato (Super Bonder ${ }^{\circledR}$ )

7. 1 seringa de $20 \mathrm{ml}$ descartável

$8.20 \mathrm{ml}$ de solução de Ringer-lactato

9. 1 lente de contato hidrofílica

10. Iodopovidona $(5 \mathrm{ml})$

\section{Descrição da técnica de uso de cianoacrilato}

1. Assepsia com iodopovidona

2. Colocação de campo cirúrgico

3. Colocação de blefarostato

4. Instilação do colírio proparacaína a $0,5 \%$ ( $1 \mathrm{ml})$

5. Retirada do epitélio da córnea com lâmina ${ }^{\circ} 15$ até $2 \mathrm{~mm}$ da borda da lesão

6. Limpeza do local a ser aplicado a cola de 2 -metil cianoacrilato

7. Retirada de líquido do local com esponja de celulose 
8. Instilação da cola de cianoacrilato com o auxílio de agulha $25 \times 7$ no local da lesão

9. Irrigação com a solução de Ringer-lactato para polimerização da cola

10. Gotejamento de colírio de ofloxacina a $0,3 \%(1$ gota $=$ $0,05 \mathrm{ml})$

11. Colocação de lente de contato hidrofílica terapêutica

12. Descarte do tubo de cola de cianoacrilato

\section{Técnica de sutura de córnea}

Materiais utilizados:

1. 1 fio Seda 4.0

2. 1 fio Nylon 9.0

3. 1 fio Nylon 10.0

4. Iodopovidona

5.1 seringa de $1 \mathrm{ml}$

6.2 seringas de $5 \mathrm{ml}$

7. 1 agulha de $25 \times 7$

8. 1 lâmina de bisturi $n^{\circ} 11$

9. 1 lâmina de bisturi $\mathrm{n}^{\circ} 15$

10. 1 ampola de metilcelulose contendo $2 \mathrm{ml}$

11. 5 esponjas de celulose

12. 1 pacote de gazes

13. 1 ampola de gentamicina na concentração de $40 \mathrm{mg} / \mathrm{ml}$

14. 1 ampola de dexametasona na concentração de $1 \mathrm{mg} / \mathrm{ml}$

15. 1 oclusor oftálmico

\section{Descrição da técnica de sutura de córnea:}

1. Assepsia com iodopovidona tópica

2. Colocação de campo cirúrgico

3. Abertura das pálpebras utilizando blefarostato ou fio seda 4.0

4. Irrigação com solução de Ringer-lactato com auxílio de seringa de $05 \mathrm{ml}$

5. Limpeza do local da lesão para melhor visualização com esponja de celulose e retirada de debris nos casos necessários

6. Sutura temporária com fio nylon 9.0 na área da lesão para manter a câmara anterior

7. Confecção de paracentese em área de limbo córneoescleral às 11:00 horas com lâmina de bisturi $n^{\circ} 11$

8. Injeção de metilcelulose na câmara anterior

9. Limpeza do local com esponja de celulose e lâmina n ${ }^{\circ} 15$ para retirada de tecido necrótico e debris, caso necessária

10. Sutura definitiva na córnea com fio nylon 10.0 (3-1-1)

11. Injeção subconjuntival de gentamicina e dexametasona diluídos ao meio

12. Limpeza da região periocular com gazes

13. Colocação de curativo oclusivo.

\section{RESULTADOS}

O preço mesmo em reais dos materiais utilizados para reparar perfuração de córnea com cianoacrilato é apresentado na tabela 1 , com seus respectivos preços. O preço mesmo total do material utilizado com o uso de cola de cianoacrilato foi de $\mathrm{R} \$ 19,86$.

\begin{tabular}{|c|c|}
\hline \multicolumn{2}{|c|}{$\begin{array}{l}\text { Tabela 1. Discriminação dos preços, em reais, dos materiais } \\
\text { utilizados para reparação de perfuração de córnea utilizadas } \\
\text { segundo a técnica de cianoacrilato }\end{array}$} \\
\hline Material & Preço em reais \\
\hline Anestésico proparacaína (1 ml) & $\mathrm{R} \$ \quad 0,81$ \\
\hline Colírio de ofloxacina $0,3 \%$ (1 gota) & $R \$ \quad 0,10$ \\
\hline Iodopolvidona & $R \$ 1,00$ \\
\hline 1 lâmina de bisturi $n^{0} 15$ & $\mathrm{R} \$ \quad 0,55$ \\
\hline 1 lente de contato descartável & $\mathrm{R} \$ 7,00$ \\
\hline 1 tubo de cianoacrilato & $R \$ 4,00$ \\
\hline 1 agulha $25 \times 7$ & $\mathrm{R} \$ \quad 0,10$ \\
\hline 1 seringa de $20 \mathrm{ml}$ & $R \$ 3,00$ \\
\hline $20 \mathrm{ml}$ de Ringer lactato & $\mathrm{R} \$ \quad 0,10$ \\
\hline 1 esponja de celulose & $\mathrm{R} \$ 3,20$ \\
\hline Preço mesmo total & $\mathrm{R} \$ 19,86$ \\
\hline
\end{tabular}

\begin{tabular}{|c|c|}
\hline Material & Preço em reais \\
\hline Fio seda 4.0 & $\mathrm{R} \$ \quad 5,71$ \\
\hline Fio nylon 9.0 & $\mathrm{R} \$ 41,67$ \\
\hline Fio nylon $10-0$ & $\mathrm{R} \$ 41,67$ \\
\hline lodopovidona & $\mathrm{R} \$ \quad 1,00$ \\
\hline Seringa de $1 \mathrm{ml}$ & $\mathrm{R} \$ \quad 1,00$ \\
\hline 2 seringas de $5 \mathrm{ml}$ & $\mathrm{R} \$ \quad 1,10$ \\
\hline 1 agulha de $25 \times 7$ & $\mathrm{R} \$ \quad 0,10$ \\
\hline 1 lâmina no 11 & $\mathrm{R} \$ \quad 0,55$ \\
\hline 1 lâmina $\mathrm{n}^{0} 15$ & $\mathrm{R} \$ \quad 0,55$ \\
\hline 1 ampola de metilcelulose & $\mathrm{R} \$ 14,70$ \\
\hline 5 esponjas de celulose & $\mathrm{R} \$ 16,00$ \\
\hline 1 pacote de gazes & $\mathrm{R} \$ \quad 5,00$ \\
\hline 1 ampola de gentamicina $40 \mathrm{mg} / \mathrm{ml}$ & $\mathrm{R} \$ \quad 5,60$ \\
\hline 1 ampola de dexametasona $2 \mathrm{mg} / \mathrm{ml}$ & $\mathrm{R} \$ \quad 2,42$ \\
\hline 1 oclusor oftálmico & $\mathrm{R} \$ \quad 0,50$ \\
\hline Anestésico proparacaína (1 ml) & $\mathrm{R} \$ \quad 0,81$ \\
\hline Preço mesmo total & $\mathrm{R} \$ 138,38$ \\
\hline
\end{tabular}

Para a técnica de sutura de córnea o material utilizado e seus respectivos preços, são apresentados na tabela 2 . O preço mesmo total do material utilizado com a técnica de sutura de córnea foi de $\mathrm{R} \$ 138,38$.

\section{DISCUSSÃO}

Em 55 milhões de trauma oculares que restringem as atividades laboriais da população atingida em um dia por ano ou mais; 750.000 casos requerem hospitalização das vítimas por ano, incluindo 200.000 traumatismos oculares perfurantes ${ }^{(18)}$.

Em nosso estudo o preço do material usado no tratamento de perfurações de córnea com a utilização da técnica de cola de cianoacrilato foi de $\mathrm{R} \$ 19,86$, enquanto que com a técnica de sutura de córnea foi de $\mathrm{R} \$ 138,38$, o que representou uma diferença de preços de R \$118,52 entre as duas técnicas, de- 
monstrando que a reparação da perfuração de córnea com a técnica de sutura representa aproximadamente seis vezes o preço comparado quando foi utilizado a cola de cianoacrilato.

Apesar de que um terço dos traumas oculares serem preveníveis, a taxa de incidência de traumas oculares perfurantes é de 2,3 em 100.000 habitantes na Alemanha, 3,6 em 100.000 habitantes na Austrália e 3,7 em 100.000 habitantes em Cingapura $^{(2,5,19)}$. Considerando uma taxa de incidência de 3,5 em 100.000 habitantes e sabendo-se que a população de Marília é de aproximadamente 200.000 habitantes, estima-se que anualmente deverão ocorrer 7 casos novos de trauma ocular perfurante na cidade de Marília; 350 casos novos na cidade de São Paulo (10 milhões de habitantes), 1.400 casos novos no Estado de São Paulo (40 milhões de habitantes) e 5.950 casos novos considerando toda nação brasileira (170 milhões de habitantes $)^{(7,20)}$.

Considerando-se a estimativa da ocorrência de 5.950 casos de trauma ocular perfurante no Brasil por ano e que hipoteticamente $20 \%$ (1.190 casos) seja passível de ser reparado com cola ter-se-ia um gasto de $\mathrm{R} \$ 23.633,40$ (1.190 casos x R \$ 19,86) com o uso da técnica com cola de cianoacrilato enquanto com a técnica de sutura de córnea ter-se-ia um gasto de $\mathrm{R} \$ 164.672,20$ (1.190 casos x R $\$ 138,38)$.

De acordo com Moschos et al a utilização da técnica com cola de cianoacrilato em perfuração de córnea com diâmetro acima de $3 \mathrm{~mm}$ tem demonstrado bons resultados ${ }^{(21)}$. Neste estudo as indicações para utilização de cola de cianoacrilato foram limitadas a lesões de até $2,5 \mathrm{~mm}$ de diâmetro, sendo que se a abrangência da indicação ampliasse para $3 \mathrm{~mm}$ ou mais como sugerido por Moschos et al, haveria um aumento de economia, uma vez que mais pacientes teriam sua perfuração de córnea reparada com a técnica com cola de cianoacrilato.

Por outro lado é importante enfatizar que perfurações maiores que $3 \mathrm{~mm}$ necessitam de maior quantidade de adesivo o que aumenta significativamente sua toxicidade. Quando utilizada em exagero causa reações inflamatórias intensas, vascularização e necrose da córnea ao redor da área tratada ${ }^{(17)}$.

Embora as colas de cianoacrilato de monômeros mais longos sejam menos tóxicas (Hystoacril Blue ${ }^{\circledR}$ ) a cola de cianoacrilato utilizada (2-metil-cianoacrilato) se polimeriza mais rápido, em presença de líquidos devido à ação de ânions levando a adesividade maior e tempo de polimerização mais prolongado ${ }^{(16-17,22-23)}$.

A cola de cianoacrilato testada é de fácil acesso, de gasto baixo e amplamente disponível em todo território brasileiro.

\section{CONCLUSÃO}

1. O gasto observado com a utilização da técnica de cianoacrilato foi de $\mathrm{R} \$ 19,86$, enquanto com a técnica de sutura de córnea foi de $\mathrm{R} \$ 138,38$.

2. O gasto observado com a utilização da técnica de cianoacrilato é menor ( $\mathrm{R} \$ 118,52)$ em relação ao gasto do procedimento de sutura de córnea.

\section{AGRADECIMENTOS}

Prof. Dr. José Augusto Alves Ottaiano - Chefe do Departamento de Oftalmologia da Faculdade de Medicina de Marília. Tutor de minha vida profissional e acadêmica e responsável pela educação ética. Prof. Dr. Marinho Jorge Scarpi - Responsável pelo Mestrado Profissionalizante em Administração da Prática Oftalmológica do Curso de Pós-graduação em Oftalmologia da UNESP. - Pelo trabalho e assistência aos alunos do Mestrado Profissionalizante. Prof ${ }^{a}$. Dr ${ }^{a}$. Ioshie Ibara Tanaka - Chefe da Disciplina de Microbiologia da Faculdade de Medicina de Marília. - Agradecido pela colaboração e ajuda.

\section{ABSTRACT}

Purpose: The aim of this study was performing a comparative evaluation of cost in small ocular perforation repair using cyanoacrylate adhesive technique Super Bonder ${ }^{\mathrm{TM}}$ (methyl-2cyanoacrylate) as compared with corneal suture technique. Methods: In order to compare evaluations of cost a cost analysis in "reais" ( $\mathrm{R} \$$ ) was conducted for both techniques according to the materials used in cyanoacrylate glue technique and the corneal suture. Results: The analysis of comparative cost of the cyanoacrylate adhesive technique in small perforations versus corneal suture showed a lower cost of the former. Conclusion: Lower cost was found for the cyanoacrylate glue technique for corneal perforation repair when compared to the corneal suture technique.

Keywords: Cornea/injury; Health care costs; Sutures/economy; Cyanocrilates/economy; Cola

\section{REFERÊNCIAS}

1. United States Eye Injury Registry. [citado 2002 Dez 28]. Disponível em: URL: http://www.useironline.org

2. Wong TY, Tielsch JM. A population - based study on the incidence of severe ocular trauma in Singapore. Am J Ophthalmol 1999;128:345-51.

3. Whitcher JP, Srinivasan M, Upadhyay MP. Corneal blindness: a global perspective. Bull World Health Organ 2001;79:214-21.

4. World Eye Injury Registry (weir on line). [citado 2002 Dez 28]. Disponível em: URL: http://www.weironline.org

5. Framme C, Roider J. Epidemiology of open globe injuries. Klin Monatsbl Augenheilkd 1999;215:287-93.

6. 1o Fórum Nacional de Saúde Ocular. Relatório Final. Brasília; 2001.

7. Dados do Censo 2000 - IBGE [online]. [citado 2002 Nov 20]. Disponível em: URL: htttp://www.ibge.gov.br.

8. Moreira ATR, Moreira Junior CA, Arana J. Causa de cegueira no Instituto de Cegos do Paraná. Arq Bras Oftalmol 1991;54:275-8.

9. Alves MR, José NK, Prado Junior J, Usuba FS, Onclinx TM, Marantes CR. Ferimento perfurante ocular: 400 casos admitidos na clínica oftalmológica do Hospital das Clínicas da Faculdade de Medicina da Universidade de São Paulo. Arq Bras Oftalmol 1995;58:342-5.

10. Vianna Filho RC, Sousa LB, Bordon AF, Freitas D. Estudo epidemiológico das perfurações oculares em acidentes automobilísticos. Arq Bras Oftalmol 1995;58:460-4.

11. McCarty CA, Fu CL, Taylor HR. Epidemiology of ocular trauma in Australia. Ophthalmology 1999;106:1847-52. 
12. Bonatti JA, Stefano JT, Matheus LCA, Oliveira GA, Suzuki H, Kara-José N. Desenvolvimento de adesivo tecidual fibrínico para uso experimental em perfurações corneanas. Arq Bras Oftalmol 1995;58:354-6.

13. Moreira Jr. CA, Freitas D, Kikuta HS. Trauma ocular. Rio de Janeiro: Editora Cultura Médica; 1997.

14. Jaffe NS. Atlas de cirurgia ocular. São Paulo: Manole; 1993. p.2-14

15. Belfort Jr. R, Kara-Jose N. Córnea clínica e cirúrgica. São Paulo: Roca; 1997. p.483-4.

16. Belfort Jr. R, Kara-Jose N. Córnea: clínica, cirúrgica. São Paulo: Roca; 1997. p.438-9.

17. Garrido C, Teles D, Koji W, Freitas D. Cola terapêutica de cianoacrilato nas perfurações corneanas. Arq Bras Oftalmol 1999;62:683-6.
18. Négrel AD, Thylefors B. The global impact of eye injuries. Ophthalmic Epidemiol 1998;5:143-69.

19. Fong LP. Eye injuries in Victoria, Australia. Med J Aust 1995;162:64-8

20. Fundação Seade. Fundação Sistema de Análises e Estatística do Estado de São Paulo. São Paulo. [citado 2002 Nov 20]. Disponível em: URL://www.seade. sp.gov.br

21. Moschos M, Droutsas D, Boussalis P, Tsioulias G. Clinical experience with cyanoacrylate tissue adhesive. Doc Ophthalmol 1996-97;93:237-45.

22. Jandinski J, Sonis S. In vitro effects of isobutyl cyanoacrylate on four types of bacteria. J Dent Res 1971;50:1557-8.

23. Lehman RA, West RL, Leonard F. Toxicity of alkyl 2-cyanoacrylate. II. Bacterial growth. Arch Surg 1966;93:447-50.

\title{
XXIX CONGRESSO DA SOCIEDADE BRASILEIRA dE RETINA E VÍtreo
}

\section{1 a 03 de abril de 2004}

Centro de Convenções de Florianópolis CENTRO SUL - SC

PROMOÇÃO: SOCIEDADE BRASILEIRA DE

\author{
RETINA E VÍTREO
}

\section{INFORMAÇÕES: AttitudePromo}

Tel./Fax: (48) 246-4388

Email: retina2004@ccrv.com.br

Home-page: retina2004.com.br 